\title{
Sustainable coastal halophyte farming for biofuel in arid regions: Site and feedwater selection using geochemical modelling
}

\author{
Qingqian Ning ${ }^{1}$, Abdul Matiin Wan², and Farrukh Ahmad ${ }^{3}$ \\ ${ }^{1} X i '$ 'an Jiaotong-Liverpool University \\ ${ }^{2}$ Axiom Learning \\ ${ }^{3}$ Environmental Health Solutions Inc.
}

August 11, 2020

\begin{abstract}
Halophyte agriculture in marginal soils using saline water offers a sustainable solution for generating biomass feedstock for carbon-neutral aviation biofuels. A full-scale sustainable energy and agriculture system (SEAS) demonstration is planned for the Abu Dhabi coast, where evaporitic gypsiferous soils pose a challenge to long-term operation because of the potential for land degradation. In this study, geochemical modelling on the Geochemist's Work Bench (GWBß) platform was employed to: (1) Evaluate the feasibility of using coastal groundwater versus seawater as irrigation feedwater; (2) determine the change in agricultural return water salinity through site-specific soils upon different seawater irrigation rates; and, (3) assess mineral deposition effects in the soil column as a function of site-specific soil characteristics at candidate sites over a one-year period of continuous seawater irrigation. Evaporation modelling was used to evaluate potential feedwater sources while varying feedwater composition and electrolyte activity coefficient models. 1-D saturated-flow advection-precipitation/dissolution modelling was utilized to assess return water quality and mineral deposition as a function of both the electrolyte activity coefficient model and the mineral composition of site-specific soils. Results pointed to seawater as the more viable feedwater option compared to coastal groundwater because of slower onset of precipitation. This effort demonstrated that soil type did not influence agricultural return water salinity (except for strongly gypsic soils) but influenced mineral precipitation under surficial evaporation conditions. Porosity loss correlated with layers of mineral deposition. The study points to the need for careful selection of land and saline water resources for the sustainable farming of halophytes.
\end{abstract}

\section{INTRODUCTION}

An estimated $3 \%$ of global anthropogenic carbon emissions can be attributed to the aviation sector, with this percentage expected to increase substantially by 2050 with growth in the aviation industry (Mezher, Rathbun, Wang, \& Ahmad, 2013). Although fossil fuel alternatives such as plant-derived biofuels have been tested in commercial aircrafts (Rahmes et al., 2009), these fuels often fail to meet the requirement of sustainability, as they compete for land and water that could otherwise be channelled into the production of food for humans and livestock (Warshay, Pan, \& Sgouridis, 2011). Recently, salt tolerant plants called halophytes have been identified as a more sustainable biofuel feedstock source, owing to the fact that these plants can be cultivated in highly saline environments, using marginal soils, and with seawater irrigation (Khan \& Duke, 2001; Warshay et al., 2011).

Successful cultivation of halophytes like Salicornia in Mexico and Eritrea using coastal soils under seawater flood irrigation conditions (Glenn et al., 2013) has fostered the possibility of a further demonstration of cultivatingSalicornia in coastal soils of Abu Dhabi in the Arabian Peninsula, this time to generate feedstock for aviation biofuels. However, the arid climate, high average seawater salinity of 45-46 g/L of the Arabian/Persian Gulf (Coles, 2003), and the prevalence of gypsiferous coastal soils containing evaporitic minerals 
(Environment Agency - Abu Dhabi, 2009) pose a significant challenge to the success of such a demonstration. The dissolution/precipitation dynamics of such saline water agriculture systems in arid coastal environments is largely unknown and can potentially cause many problems, including soil salinization, groundwater impact, and loss in yield over time owing to poor drainage resulting from mineral deposition (Breckle, 2009). Hence, there is a pressing need for anticipating some of these problems by developing a modelling framework that considers soil type and feedwater quality.

Gypsum and anhydrite, which are prevalent in the coastal soils of Abu Dhabi, are known to show unusual dissolution characteristics when coming in contact with seawater. Generally, the dissolution of evaporitic minerals occurs when they come into contact with porewater that is undersaturated for the mineral. The undersaturation of gypsum and anhydrite holds true not only for freshwaters, but also for seawater where both of these minerals are significantly undersaturated when compared to carbonate minerals like calcite and aragonite (Hoareau, Monnin, \& Odonne, 2011). Additionally, the presence of dissolved halite $(\mathrm{NaCl})$ in seawater is reported to enhance the solubility of both gypsum and anhydrite (Bethke, 2011; Serafeimidis \& Anagnostou, 2015). Hence, the dissolution/precipitation dynamics of gypsum are likely to play a role in sustained operation of saline water farming of halophytes in Abu Dhabi. Modelling the precipitation/dissolution reaction term for gypsum and other minerals couples their interfacial mass transfer term with their saturation index (the ratio of their ion activity product and their pure phase solubility product). In turn, ion activities in saline water are a function of ionic strength and are estimated using ion activity coefficient models such as the B-dot model and the Pitzer ion interaction model (Bethke, 2011; Prausnitz, Lichtenthaler, \& de Azevedo, 1999). Such geochemical complexities must be taken into account when modelling even the most simplified systems representing seawater farming.

In this study, evaporation modelling was conducted to evaluate the available coastal feedwater sources, i.e., the Arabian/Persian Gulf seawater and coastal shallow groundwater. It should be noted that significant evaporation from coastal sabkhas, playas, and saline lakes is known to bring about rapid (i.e. in a few days) onset of gypsum precipitation (Reznik, Ganor, Gruber, \& Gavrieli, 2012; Yechieli \& Wood, 2002). Following this exercise, a 1-D saturated-flow advection-precipitation/dissolution model was applied to regional sitespecific soil mineralogies obtained from the Abu Dhabi Soil Survey while applying an evaporative load to the upper soil layers. The model was then used as a predictive tool to: (1) determine the change in agricultural return water salinity with different seawater irrigation rates, and (2) assess the effect of soil characteristics on mineral deposition in the soil column (e.g., change in mineral content and porosity loss), over a oneyear period of continuous seawater irrigation. The study points to careful selection of land and saline water resources for the sustainable farming of halophytes, especially in arid coastal regions where evaporitic soils and high evapotranspiration conditions are likely to bring the onset of land degradation over long-term operation.

\section{MATERIALS AND METHODS}

\subsection{Analytical Methods}

Aqueous dissolved ion analysis was carried out on a Dionex ${ }^{\circledR}$ ICS 3000 reagent-free ion chromatography system (Dionex Corp., Sunnyvale, CA, USA), using IonPac ${ }^{\circledR}$ CS12A and IonPac ${ }^{\circledR}$ AG19 columns. Cation analysis was carried out in isocratic mode, set to run for 20 minutes, while anion analysis was carried out in gradient mode with a total run time of 35 minutes. Methanesulfonic acid (MSA, $20 \mathrm{mM}$ ) and potassium hydroxide (KOH, $10 \mathrm{mM}$ ) were applied as eluents for cations and anions, respectively. Column temperature was set to $30^{\circ} \mathrm{C}$. Sample injection volume of $1 \mathrm{~mL}$ was applied for all runs. Dilution factor of 351 and 3-point calibration were adopted for result quantification, using the Chromeleon ${ }^{\circledR}$ software v. 6.80 .

\subsection{Geochemical Modelling}

All model development and simulations were carried out using the Geochemist's Workbench ${ }^{\circledR}$ software (GWB, v. 9.0, Aqueous Solution LLC, Champaign, Illinois, USA) using the React module to solve chemical equations and the $\mathrm{X} 1 \mathrm{t}$ module to solve transport equations. 


\subsubsection{Model Equations}

Overall reactive transport in one-dimension was governed by the general advection-dispersion-reaction equation:

$\underline{\partial\left(\vartheta_{i}^{\circ}\right)}$

english $\partial t=\frac{\partial}{\partial x}\left(\theta D_{L} \frac{\partial C_{i}}{\partial x}\right)-\frac{\partial}{\partial x}\left(\vartheta_{x} C_{i}\right)+\vartheta R_{i}(1)$

For screening-level analysis, dispersion was neglected as dispersion is an empirical field parameter, simplifying Equation (1) to the following advection-reaction model:

$\underline{\partial\left(\vartheta_{i}^{\circ}\right)}$

english $\partial t=-\frac{\partial}{\partial x}\left(\vartheta_{x} C_{i}\right)+\vartheta R_{i}(2)$

Precipitation-dissolution kinetics of a mineral were described by the following chemical equation:

$R_{i}=\left(\frac{A_{s}}{V}\right) k_{+}\left(1-\frac{Q}{K}\right)(3)$

A glossary of terms and their units used in the above equations is presented in Table 1 .

\subsubsection{Evaporation Modelling}

Evaporation modelling was conducted for different options of feedwater, including Arabian Gulf seawater and coastal shallow groundwater in Abu Dhabi represented by the shallow groundwater at the Masdar Institute site (Table 2 ). Equation (3) was used by itself in non-flowing evaporation modelling to evaluate two different activity coefficient models for electrolytes, namely, the B-dot model and the Pitzer ion interaction model. The B-dot model (Bethke, 2011; Sandler, 2006), a variant of the Debye-Huckel activity coefficient model, was used to determine the ion activity product in Equation 4. The B-dot model is a function of the solution ionic strength, species charge, ion size, and empirical coefficients (Plummer, Jones, \& Truesdell, 1976). This model is considered to be accurate to an ionic strength between 1-2 moles* $\mathrm{kg}^{-1}$ of water (Plummer et al., 1976). Note that average seawater ionic strength is only $\sim 0.7$ moles $\mathrm{kg}^{-1}$. However, in situations of strong evapotranspiration or contact with hypersaline groundwater, porewater salinity can be high enough such that measured values deviate strongly from B-dot model solubility predictions. In such cases, a more accurate approach is to incorporate ion interactions, such as those used by the Pitzer ion interaction model denoted in GWB by the PHRQPITZ virial expansion model (Ptacek \& Blowes, 2000).

In GWB software, evaporation is modelled as mass of water removed and mineral oversaturation is determined using a selected activity coefficient model. Both, B-d

ot and PHRQPITZ, activity coefficient models were employed to model the removal of $>99 \%$ mass of water to predict the total mass of precipitate formed as well as its mineral composition.

\subsubsection{Site Soil Data}

Five coastal sites in the Abu Dhabi Emirate were identified by the Abu Dhabi Urban Planning Council (www.upc.gov.ae) as potential sites for the halophyte farming field demonstration (Figure 1 ). The soil types at these sites were determined from the Abu Dhabi Soil Survey (Environment Agency - Abu Dhabi, 2009), which also contained detailed physical and chemical composition (including mineral stratigraphy) of each soil type. Soil types AD128, AD129, AD134, AD146, AD157, and TF (tidal flats) were identified as being present at the five proposed sites. Owing to the shallow groundwater table possibly encroaching into the root zone at the locations of soil types AD128, AD129, and TF, these soil types were excluded from further analysis. The remaining soil types, AD134, AD146, and AD157, were chosen for geochemical modelling (Tables 3(a)-(c) ). The total soil column depth was taken from the depth-to-groundwater in the Soil Survey at the location of the potential sites.

\subsubsection{Model Discretization and Initial and Boundary Conditions for Continuous-Flow Reactive Transport}


A one-dimensional finite-difference numerical model depicting reactive transport under saturated-flow conditions was developed using the equations previously described on the GWB platform. The inlet boundary condition $(\mathrm{x}=0$ at $\mathrm{t}>0)$ was specified by composition of the influent feedwater (Table 2 ). Porewater ionic species concentrations at equilibrium with feedwater (i.e., no flow) were taken as the initial condition at $t=0$ along the length of the soil column. The mineral stratigraphy data for each soil type from the Soil Survey (Tables 3(a)-(c) ) was mapped on to a one-dimensional saturated-flow finite-difference model with nodecentered cell dimensions of $10 \mathrm{~cm}$ (Figure 2 ). An average annual evaporation of 2,000 $\mathrm{mm}$ was assumed for the coastal UAE region (International Center for Biosaline Agriculture, 2013), while rain precipitation was assumed to be negligible (Statistics Center Abu Dhabi (SCAD):www.scad.gov.abudhabi ). The evaporation loading was applied to only the top 3 surficial cells (cell 1 at $1 \mathrm{~m}^{3} / \mathrm{m}^{2} / \mathrm{yr}$; cells 2 and 3 at 0.5 $\mathrm{m}^{3} / \mathrm{m}^{2} / \mathrm{yr}$ ). Initial porewater conditions were assumed to be at equilibrium with the mineral content in each cell mapped from the Soil Survey. Feedwater was assumed to have the reported average ionic composition of Arabian/Persian Gulf sweater (Table 2 ). Equations (2) and (3) governed the finite difference model, which are solved in GWB using an "operator splitting method" where the system of equations are solved sequentially for transport (Figure 2 ) at each node before moving onto the next node. Default mineral-specific mass transfer coefficients for precipitation/dissolution in GWB were utilized for the various minerals present in the soil. Both, B-dot and PHRQPITZ, activity coefficient models were employed both in the agricultural return simulations and in the one-year-long continuous-flow runs. TDS of the leachate return was calculated from the ion concentration data in GWB. Three different annual irrigation water loadings, $2.5 \mathrm{~m}, 3 \mathrm{~m}$, and $4 \mathrm{~m}$, were applied to each soil column model corresponding to leachate fractions of $0.25,0.50$, and 1.0 , respectively. Leachate fraction is the ratio of water effluent to influent into the column and is a measure of the amount of water loss owing to evapotranspiration losses in comparison to total feedwater loading.

\section{RESULTS}

Four candidate coastal feedwaters for halophyte irrigation (Arabian Gulf Seawater, and coastal groundwater from Masdar Wells 2, 3, and 4) were evaluated via evaporation modelling simulation, where water mass was removed incrementally to evaluate the profile of minerals deposited both individually (Figure 3 ) and cumulatively (Figure 4 ). As mentioned earlier, two different electrolyte activity coefficient models, B-dot and PHRQPITZ, were employed to calculate both the type and quantity of minerals deposited using Equation (3).

A reactive transport model was utilized to assess agricultural return flow salinity as a function of irrigation loading and soil type. Three different annual irrigation water loadings, $2.5 \mathrm{~m}, 3 \mathrm{~m}$, and $4 \mathrm{~m}$, were applied to each soil column model. Both electrolyte activity coefficient models, B-dot and PHRQPITZ, were employed to estimate total salinity (in terms of aqueous TDS levels) in the agricultural return from the bottom of the soil column. The results of this exercise are presented inFigure $\mathbf{5}$.

Reactive transport modelling was used again to demonstrate changing solid phase mineral profiles in the irrigated soil column after continuous irrigation for a period of one year. In addition, changes in porosity in the soil column after continuous irrigation for a period of one year were demonstrated. Results for mineral deposition profiles and changes in porosity along the soil column are presented inFigure 6 .

\section{DISCUSSION}

\subsection{Effects of Evaporation and Activity Coefficient Models on Feedwater Options}

The evaporation progress of four different potential sources of irrigation water, three coastal shallow groundwater sources and mean Arabian Gulf seawater, each having a different composition (Table 2 ), was modelled as an isothermal water depletion using two different activity coefficient models, B-dot and PHRQPITZ. The results were normalized by the total mineral mass in each sample so that the onset of precipitation could be compared between different samples and between the two activity coefficient models. The final results from this exercise are presented in Figures 3 and 4.

In general, the difference in mineral precipitation between the two activity coefficient models became more 
pronounced with increasing ionic strength and salinity, with the least difference obtained for Arabian Gulf seawater, which had the lowest salinity of the four potential feedwater sources. The difference was especially pronounced for the hypersaline coastal shallow groundwater samples, including Masdar Well 4 water, which has a similar salinity and expected composition as the shallow groundwater at sites D and E (Figure 1 ). These results corroborate assertions by other researchers (Zhang, Zheng, \& Wan, 2005) that the Pitzer ion interaction model is more suitable for activity calculations in strong electrolytes like hypersaline waters and brines. PHRQPITZ, the Pitzer virial expansion model, consistently showed an earlier onset of precipitation (i.e., conversely, less dissolution) for all feedwater sources. Also, since the B-dot model is a Debye-Huckel variant and depends solely on ionic strength, it fails to incorporate ion interactions between different types of ions, which can be better modelled using PHRQPITZ. For this reason, the salt composition of the precipitate showed variation between the two models (Figure 3 ), especially for the groundwater samples. The evaporation modelling exercise clearly demonstrated that the coastal groundwater is a poor candidate for use as irrigation water in saline water farming of halophyte plants because of its hypersaline characteristics, presumably owing to a significant salt flux from underlying evaporite deposits (Sanford \& Wood, 2001) and up wicking of shallow groundwater resulting in rapid evaporation (Imes \& Wood, 2007). The results also demonstrated that Arabian Gulf seawater is unlikely to undergo rapid precipitation until almost $90 \%$ of its water mass has been evaporated. In addition, this exercise displayed the least deviations in precipitation modelling predictions between the two activity coefficient models for seawater, confirming that B-dot could be used to model seawater evaporation with limited error. B-dot also allows for temperature correction, a feature unavailable with PHRQPITZ, which can be useful in the future to model the summer months in Abu Dhabi when the ambient temperatures can approach $50{ }^{\circ} \mathrm{C}$.

\subsection{Agricultural Return Flow Salinity as a Function of Irrigation Loading and Soil Type}

Agricultural return flow salinity was modelled using 1-D reactive transport with an evaporative loading applied to the top 3 cells as described earlier. Arabian Gulf seawater was selected as the irrigation feed water and model layers were populated with mineral composition using site-specific information from the Abu Dhabi Soil Survey. AD134 was a strongly gypsic soil (Table 3(a)) with high gypsum occurrence in all cells or layers, whereas AD146 (Table 3(b) ) was a carbonate-rich soil with almost no gypsum presence. Finally, soil type AD157 (Table 3(c) ) was a mildly gypsic soil with high gypsum content only in cells 3 and 4 from the ground surface. Three different annual irrigation water loadings, $2.5 \mathrm{~m}, 3 \mathrm{~m}$, and $4 \mathrm{~m}$, were applied to each soil column model corresponding to leachate fractions of $0.25,0.50$, and 1.0 , respectively.

The results from the reactive transport modelling for the three soil types after one calendar year of continuous flow are presented inFigure $\mathbf{5}$. Increased irrigation loading was found to generally correlate with a decrease in return water salinity. This result appears to corroborate the "salt penalty" effect described by Edward P. Glenn, J. Jed Brown, and Eduardo Blumwald (1999), which essentially attributes this effect to a combination of lower dissolution of minerals from the soil at faster flowrates and an averaging of the mineral dissolution over the larger volumetric flow. The highest return water salinity (i.e., 56,500 ppm TDS and higher) was observed for the high gypsum containing AD134 soil type using the B-dot activity coefficient model. The discrepancy in salinity prediction using the two different models was most pronounced for this soil type, with PHRQPITZ predicting a salinity in the range of only 53,500 - 54,000 ppm TDS. Meanwhile soil types AD146 and AD157, the carbonate-rich and gypsum-deficient soils, displayed a close match between the two different activity coefficient models employed. These results suggest that unlike the PHRQPITZ model, the B-dot activity coefficient model appears to estimate a much higher solubility for gypsum at higher ionic strengths. This result would require field verification using soil core analysis during initial pilot studies.

\subsection{Effects of mineral precipitation within the soil matrix}

Deposition of minerals under 1-D saturated flow transport conditions was modelled using both B-dot and PHRQPITZ activity coefficient models. However, the results presented here belong only to the PHRQPITZ runs, as this model was concluded to be a better predictor of deposition and solubility behavior for saline water from prior sections of the study.Figure 6 presents the mineral deposition profile with depth from seawater for the three different soil types at the one-year mark of irrigation. The minerals dominating depo- 
sition were carbonates and sulfates, namely, gypsum and dolomite for AD134; dolomite and magnesite for AD146; and, calcite, gypsum, and dolomite for AD157. Calculations of mineral deposition in this continuous model are based on the degree of supersaturation and might not reflect true deposition for the case of especially dolomite, which requires microbial mediation or the presence of organic polymers for deposition under ambient temperature and pressure conditions (Warthmann, Van Lith, Vasconcelos, McKenzie, \& Karpoff, 2000). Hence, the deposition of dolomite in particular can be taken as a surrogate for the precipitation of carbonates of the calcium and magnesium variety.

The zone of mineral deposition in each soil type also presented interesting results. For example in AD134, gypsum deposition peaked from 40 to $70 \mathrm{~cm}$ below ground surface (bgs), while dolomite did not peak until a depth of $120 \mathrm{~cm}$ bgs and greater. Similarly, dolomite was the dominant mineral deposited in the top half of the AD146 soil column while magnesite was the dominant mineral in the second half of the modelled soil column. AD146 soil column never exceeded equilibrium saturation of gypsum because of this soil type's low solid-phase gypsum mineral content. In contrast, AD157 displayed dual depositional peaks of calcite (10-20 am and 40-60 cm bgs) with a peak of gypsum deposition in between $(20-40 \mathrm{~cm}$ bgs $)$ the calcite peaks.

Porosity loss owing to mineral deposition was significant for all soil types (AD134: 38\% - 13\%; AD146: 37\% - 14\%; AD157: 33\% - 9\%), with the mineral deposition peaks correlating well with zones of maximum porosity loss (Figure 6 ) for the modelled soil types AD134 and AD146. In AD134, minimum porosity was observed where gypsum and dolomite deposition peaks occurred, while the same was true for AD146 where the dolomite deposition peak occurred. Conversely, AD157 displayed the greatest porosity loss in shallow layers up to a depth of $45 \mathrm{~cm}$ bgs, corresponding to only the first two mineral peaks, i.e. calcite followed by gypsum. From these results of seawater application to soils, it appears that evaporation in shallow calcite-rich soils (AD157) leads to the most significant porosity problems, followed by the deposition of gypsum when seawater flows from gypsum-rich layers to zones with lower gypsum content. Deeper precipitation might be a more challenging operational and land degradation problem because the soil at depth cannot be easily excavated or rehabilitated between halophyte planting cycles. Furthermore, potential porosity loss problems might require a different mode of irrigation, such as blending of seawater with freshwater, or alternating between periods of seawater and freshwater (or brackish water) application.

\section{CONCLUSIONS}

Evaporation modelling of saline feedwater sources showed that evaporation using the PHRQPITZ model started to precipitate minerals earlier than the widely used B-dot activity coefficient model. In addition, the higher salinity of feedwater, e.g., coastal shallow groundwater, contributed to rapid precipitation of larger amounts and variety of mineral mass. Furthermore, for seawater, the difference in total mineral precipitation prediction was minimal between the two activity coefficient models.

A 1-D continuous-flow simulation was performed under surficial evaporation conditions in the different coastal soils of Abu Dhabi. The results demonstrated the following: (1) An inverse correlation between seawater loading and agricultural return water salinity; (2) soil type did not have a significant influence on the salinity of agricultural return water, except for strongly gypsic soils for which the B-dot model predicted a 5-6\% higher salinity than PHRQPITZ; (3) mineral precipitation modelled under seawater application was highly influenced by the original coastal soil type and the solid phase mineral content in its different layers for calcite-rich soils, the influence of shallow water evaporation proved to be a strong catalyst for deposition, while gypsum-rich soils showed a dissolution-reprecipitation phenomena; and, (4) porosity loss occurred in all cells, with mineral deposition zones generally correlating with zones of maximum porosity loss. The study demonstrated geochemical modelling to be a vital tool for testing saline water irrigation scenarios in support of sustainable halophyte farming thereby preventing potential future land degradation.

\section{ACKNOWLEDGEMENTS}

This work was funded under Grant No. 12XZBA2 from the Sustainable Bioenergy Research Consortium (SBRC) originally at the Masdar Institute and currently housed at Khalifa University, Abu Dhabi, United Arab Emirates (https://www.ku.ac.ae/project/\#1543911500621-d9590b82-ff45). 


\section{CONFLICT OF INTEREST STATEMENT}

The authors have no conflicts of interest to declare.

\section{ORCID}

Farrukh Ahmad: https://orcid.org/0000-0003-1405-220X

\section{DATA AVAILABILITY STATEMENT}

Data sharing not applicable - no new data generated, or the article describes entirely theoretical research.

\section{REFERENCES}

Bethke, C. M. (2011).Geochemical and Biogeochemical Reaction Modeling (2nd ed.). Cambridge, UK: Cambridge University Press.

Breckle, S.-W. (2009). Is Sustainable Agriculture with Seawater Irrigation Realistic? Salinity and Water Stress (pp. 187-196): Springer.

Coles, S. L. (2003). Coral species diversity and environmental factors in the Arabian Gulf and the Gulf of Oman: a comparison to the Indo-Pacific region : National Museum of Natural History, Smithsonian Institution, Washington, DC, USA.

Edward P. Glenn, J. Jed Brown, \& Eduardo Blumwald. (1999). Salt tolerance and crop potential of halophytes. Plant Sciences, 18 (2), 227-255. doi: doi.org/10.1080/07352689991309207

Environment Agency - Abu Dhabi. (2009). Soil Survey of Abu Dhabi Emirate. Abu Dhabi, United Arab Emirates: Environment Agency Abu Dhabi.

Glenn, E. P., Anday, T., Chaturvedi, R., Martinez-Garcia, R., Pearlstein, S., Soliz, D., . . Felger, R. S. (2013). Three halophytes for saline-water agriculture: An oilseed, a forage and a grain crop. Environmental and experimental botany, 92 , 110-121. doi: doi.org/10.1016/j.envexpbot.2012.05.002

Hoareau, G., Monnin, C., \& Odonne, F. (2011). The stability of gypsum in marine sediments using the entire ODP/IODP porewater composition database. Marine Geology, 279 (1), 87-97. doi: doi.org/10.1016/j.margeo.2010.10.014

Imes, J. L., \& Wood, W. W. (2007). Solute and isotope constraint of groundwater recharge simulation in an arid environment, Abu Dhabi Emirate, United Arab Emirates.Hydrogeology Journal, 15 (7), 1307-1315. doi: doi.org/10.1007/s10040-007-0177-x

International Center for Biosaline Agriculture. (2013). Weather Data. from http://www.biosaline.org/weatherdata.aspx

Khan, M. A., \& Duke, N. C. (2001). Halophytes-A resource for the future. Wetlands Ecology and Management, 9 (6), 455-456.

Mezher, N., Rathbun, W. E., Wang, H., \& Ahmad, F. (2013). Chemical Composition and Screening-Level Environmental Contamination Risk of Bioderived Synthetic Paraffinic Kerosene (Bio-SPK) Jet Fuels. Energy E3 Fuels, 27 (7), 3830-3837. doi: doi.org/10.1021/ef400648j

Plummer, L., Jones, B., \& Truesdell, A. (1976). WATEQ, a computer program for calculating chemical equilibrium of natural waters : U.S. Geological Survey, Washington, DC, USA.

Prausnitz, J. M., Lichtenthaler, R. N., \& de Azevedo, E. G. (1999). Molecular Thermodynamics of FluidPhase Equilibria (Third ed.). Upper Saddle River, New Jersey: Prentice-Hall.

Ptacek, C., \& Blowes, D. (2000). Predicting sulfate-mineral solubility in concentrated waters.Reviews in Mineralogy and Geochemistry, 40 (1), 513-540. doi: doi.org/10.2138/rmg.2000.40.11 
Rahmes, T. F., Kinder, J. D., Henry, T. M., Crenfeldt, G., LeDuc, G. F., Zombanakis, G. P., . . Juenger, J. A. (2009). Sustainable bio-derived synthetic paraffinic kerosene (Bio-SPK) jet fuel flights and engine tests program results. Report No. AIAA, 7002 .

Reznik, I. J., Ganor, J., Gruber, C., \& Gavrieli, I. (2012). Towards the establishment of a general rate law for gypsum nucleation. Geochimica et Cosmochimica Acta, 85 , 75-87. doi: doi.org/10.1016/j.gca.2012.02.002

Sandler, S. I. (2006).Chemical, Biochemical, and Engineering Thermodynamics . Hoboken, NJ, USA: John Wiley \& Sons.

Sanford, W., \& Wood, W. (2001). Hydrology of the coastal sabkhas of Abu Dhabi, United Arab Emirates.Hydrogeology Journal, 9 (4), 358-366. doi: doi.org/10.1007/s100400100137

Serafeimidis, K., \& Anagnostou, G. (2015). The solubilities and thermodynamic equilibrium of anhydrite and gypsum. Rock Mechanics and Rock Engineering, 48 (1), 15-31. doi: doi.org/10.1007/s00603-014-0557-1

Warshay, B., Pan, J., \& Sgouridis, S. (2011). Aviation industry's quest for a sustainable fuel: Considerations of scale and modal opportunity carbon benefit.future science, 2 (1), 33-58. doi: doi.org/10.4155/bfs.10.70

Warthmann, R., Van Lith, Y., Vasconcelos, C., McKenzie, J. A., \& Karpoff, A. M. (2000). Bacterially induced dolomite precipitation in anoxic culture experiments. Geology, 28 (12), 1091-1094. doi: doi.org/10.1130/00917613(2000)28<1091:BIDPIA $>2.0$. CO;2

Yechieli, Y., \& Wood, W. W. (2002). Hydrogeologic processes in saline systems: playas, sabkhas, and saline lakes. Earth-Science Reviews, 58 (3), 343-365. doi: doi.org/10.1016/S0012-8252(02)00067-3

Zhang, G., Zheng, Z., \& Wan, J. (2005). Modeling reactive geochemical transport of concentrated aqueous solutions. Water resources research, 41 (2). doi: doi.org/10.1029/2004WR003097

\section{Hosted file}

Tables_and_FigureCaptions_Ning_etal_LDD_2020.docx available at https://authorea.com/ users/349979/articles/474941-sustainable-coastal-halophyte-farming-for-biofuel-in-aridregions-site-and-feedwater-selection-using-geochemical-modelling

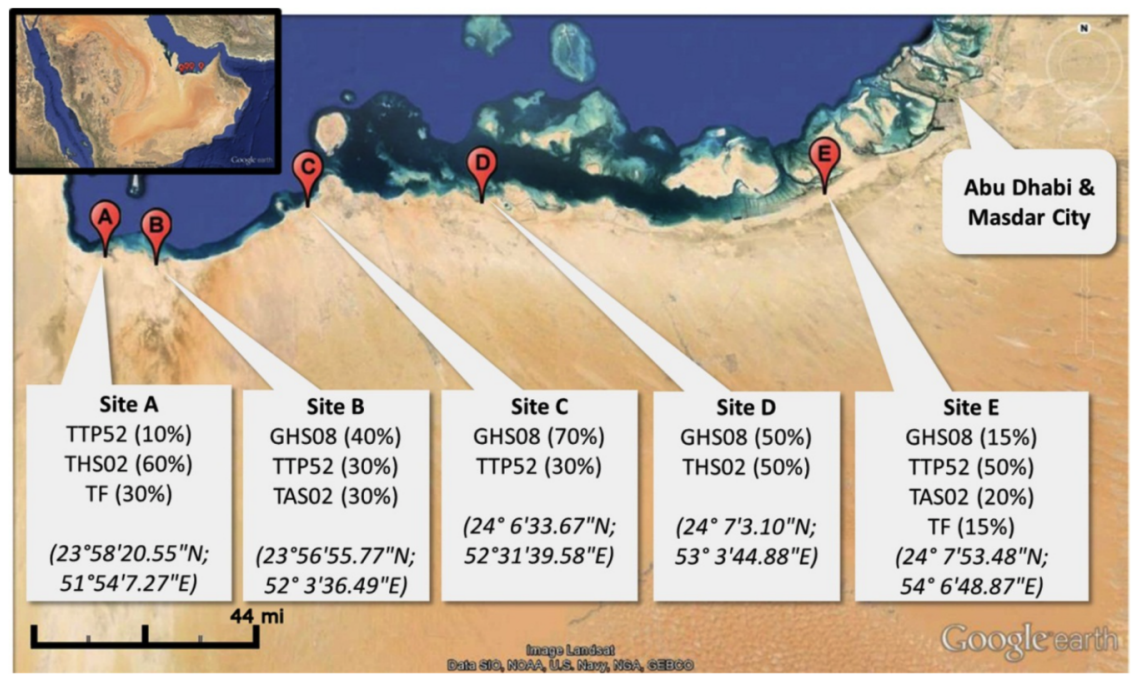

\section{Hosted file}

Figures_Ning_etal_LDD_2020.pdf available at https://authorea.com/users/349979/articles/ 474941-sustainable-coastal-halophyte-farming-for-biofuel-in-arid-regions-site-and- 
feedwater-selection-using-geochemical-modelling 